\title{
Investigation on the electric field strength radiated from G.fast data carrying copper telecommunication network
}

\author{
Josip MILANOVIC*, Snjezana RIMAC-DRLJE
}

\begin{abstract}
G.fast technology provides low cost ultra-fast broadband by transmitting high frequency signals through existing copper telecommunication network. Unfortunately, copper telecommunication network is not originally designed for data transmission on high frequencies, resulting with cable radiation when G.fast signal is transmitted. This radiation can interfere with radio services operating in the same frequency range and cause serious disturbances of the radio signal reception, thus disabling radio services to operate as intended. In order to limit radiation from telecommunication network various limits have been proposed. This paper gives the comparison between defined radiation limits and measurements of the E-field radiation from the unshielded copper telecommunication cable (TK 33-U) when G.fast (profile 106a) signal is transmitted. The results show that limit values proposed in ITU-T K.60 and FCC Volume 47 Part 15 recommendation overestimate while radiation limits proposed in ECC/REC/(05)04 recommendation underestimate radiation from TK 33-U cable. Additionally, measurement results show that E-field strength is below the ITU and FCC recommended limits, even when the unbalanced cable is used.
\end{abstract}

Keywords: ECC/REC/(05)04; FCC Volume 47 Part 15; G.fast; ITU-T K.60; radio frequency interference

\section{INTRODUCTION}

Over the last decade, users demand for high speed broadband access increased dramatically. According to some prediction, within 5 years users will expect to have 1 Gbps connection. Such high throughput will enable services such as 3DTV, TVOD, Online Gaming, Cloud platforms, Internet of Things (IoT), etc. As users demands increase, telecommunication operators are forced to look for a newer technologies which will better address those increased user expectations. Several technologies have been imposed such an acceptable solution for achieving such high user demands. Virtually unlimited bandwidth, electromagnetic immunity and low signal attenuation make fiber-optic technology as a most suitable network solution that will meet the user need for a long time [1]. Although fiber-optic technology is characterized by many advantages, there are also some disadvantages that must be taken into account, such as high installation cost and low availability (e.g. in the rural areas).

On the contrary to the fiber-optic network, copper telecommunication network is already deployed basically everywhere. That is the main reason why operators are turning to that final stretch of copper wire to unlock the extra bandwidth, enabling realization capacity demanding services that users today expect to have. Technology that enables broadband services over existing copper telecommunication infrastructure is digital subscriber line (DSL) technology. According to the required data rate, different variants of DSL technologies are provided. Technology that enables data rate up to $1 \mathrm{Gbps}$ (ultra-fast broadband) at distance up to $250 \mathrm{~m}$ over copper telecommunication network is G.fast technology [2]. Such high throughput is achieved by using considerably wider frequency bandwidth compared with frequency bandwidth used by other DSL technologies (e.g. ADSL2 and VDSL2). Unfortunately, increasing throughput by increasing frequency bandwidth has its disadvantages. It is known that copper wire is not a perfect transmission medium and that part of the signal energy is radiated in the air when the signal passes through the wire. The radiated electromagnetic field is a potential source of interference to other services operating in the same frequency range causing that radio service stops to operate as it was intended. The effect of interference varies from causing degradation of signal quality to making the radio services completely unusable. Irrespective of the effects caused by interference, the source of the interference must be found and eliminated as soon as possible. Radio services that can be affected by cable radiation when G.fast signal is transmitted through copper telecommunication networks are: government services, broadcasting services, aeronautical services, maritime services, safety of life radio services, amateur services, etc. Some of the mentioned services play a very important role in a public safety or military services where no interferences may be allowed. To provide some order and to minimize the presence of interference in the frequency spectrum, telecommunication regulation authorities (national or international) provide various radiation limits.

The purpose of this paper is to investigate the electric field (E-field) radiation level from the unshielded balanced TK 33-U cable when G.fast (profile 106a) signal is transmitted. Additionally, comparison between measured radiation values and mostly used radiation limits value is given. This paper has the following organization: basic information about telecommunication access network is given in Section 2, and information about G.fast technology used in this research is given in Section 3. In Section 4, radiation limits for cable transmission networks are presented. Section 5 provides information about the measurement methodology and procedure, while measurement results, with the evaluation of the E-field radiation, are presented in Section 6. Conclusion remarks are given in Section 7.

\section{TELECOMMUNICATION ACCESS NETWORK}

To transmit data signal from one location to another, a transmission medium is required. There are three types of the transmission media that are used for these purposes [3]: copper cable, fiber-optic cable and radio. Each of this transmission media has advantages and disadvantages, and their application depends on purpose, implementation cost, 
availability and transmission reliability. Radio, or wireless transmission media, is characterized by lower start-up cost, high mobility and adaptability, while disadvantages that limit the greater use of this medium are susceptibility to cochannel interference, signal degradation with distance and attenuation due to interaction with physical obstacles. Contrary to the radio transmission, fiber-optic is characterized with reliable data transmission and immunity to electromagnetic and radio-frequency interferences. This technology is also characterized by a large transmission capacity. Although from capacity point of view, fiber-optic is ideal media, its availability is still limited. On the other hand, copper cables are already deployed in houses and business premises. That reduces investments cost and installation time, and makes broadband access over copper cable more readily available.

To reduce the cost and installation complexity, operators combine use of fiber-optic with existing copper infrastructure in a way that fiber-optic is used from central office (CO) to the distribution point unit (DPU), and copper cable is used from the DPU to the customer premises equipment (CPE) [4]. Part of the telecommunication network from the DPU to the CPE can be underground and overhead, as is shown in Fig. 1. Radiation from the telecommunication network can interfere with radio services operating in the same frequency range only when overhead cables are used while radiation from underground cables can be neglected. This is due to the fact that overhead cables, unlike the underground ones, can be placed close to the radio system receiving antenna. The level of interference depends also on the cable structure (flat or twisted cable), shielding, physical orientation of the cable and twist length of the wires in the cable.

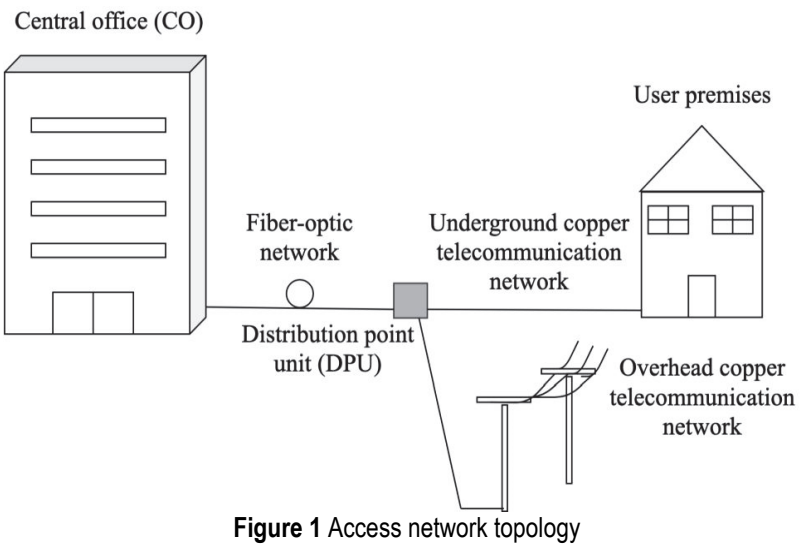

The most common technique used for reduction of cable radiation is use of twisted-wire pairs (twisted cables). These cables consists of two insulated wires twisted around each other with twisting length that is less than $\lambda_{\min } / 4$, where $\lambda_{\min }$ represents minimal wave length of the signal in the cable. Radiation reduction in twisted-wire pair comes from the fact that the two wires carry signals which are equal by magnitude and opposite by sign, resulting with mutual field cancellation generated by the cable as shown in Fig. $2[5,6]$. The ability of cable to reduce the effect of radiation is measured by its balance, which is defined as the ratio between common mode signals (those between cable and earth ground) and differential mode signals (those between the two wires of the pair) [7]. The balance of the cable, $b_{\mathrm{v}}$, is usually defined in terms of voltage ratio and numerically $b_{\mathrm{v}}$ is given as [5]:

$$
b_{\mathrm{v}}=\frac{U_{\mathrm{com}}}{U_{\text {diff }}}
$$

where $U_{\text {diff, }}$ is differential mode voltage and $U_{\text {com, }}$ is common mode voltage. In the decibel scale, the cable balance is often described as a longitudinal conversion loss (LCL), defined as

$$
L C L=-20 \cdot \log _{10}\left(b_{\mathrm{v}}\right), \mathrm{dB} \text {. }
$$

When cable is fully symmetric only differential voltage is fed in the cable, while in asymmetric cable, $U_{\text {diff, }}$ is converted to common mode voltage, causing unbalances of the cable (e.g. one wire from the twisted-wire pair is disconnected) [5].

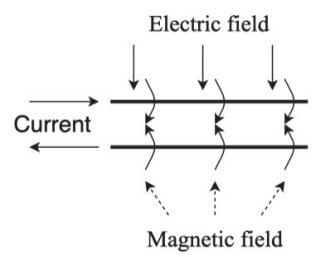

a)

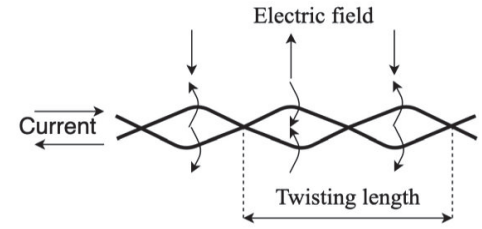

b)

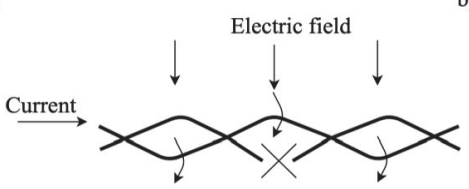

Figure 2 An electromagnetic field radiation by: a) flat cables; b) twisted cables; c) unbalanced cables

When the unbalanced cable is used, mechanism of cancelation of radiated energy from the twisted-wire pairs starts to fail, cable starts to act as an antenna and radiation from cable increases what leads to electromagnetic compatibility (EMC) issues [8]. To avoid such scenario, cable parameters should be continuously monitored by the operator, and if necessary, cable repair or cable replacement should be done as soon as possible.

\section{FUNDAMENTALS OF G.fast TECHNOLOGY}

Demand for ultra-fast broadband today has largely been driven by the new applications and services that consume more bandwidth. Technology that attracts increasing interest from operators looking to provide ultrafast broadband is G.fast. G.fast is a new DSL technology that provides aggregate data rate up to $1 \mathrm{Gbps}$ over a single copper twisted-wire pair [9]. This technology also reduces maintenance cost and provides tremendous agility and enables operators to offer capacity demanding services that contemporary users expect to have. According to some predictions, data rate reached by the G.fast will meet throughput requirements even in the most demanding households over the next 10 to 20 years. To reach such high data rate, G.fast uses improved vectoring technology and very large frequency bandwidth. 
Based on the used frequency range International Telecommunication Union (ITU) defined two profiles; profile 106a uses frequency range from 2,2 $\mathrm{MHz}$ to 106,0 $\mathrm{MHz}$, while profile 212a uses frequency range from 2,2 $\mathrm{MHz}$ to 212,0 $\mathrm{MHz}$ [10]. To further increase ultra-fast broadband, ITU proposed new standard known as Multigigabit fast access to subscriber terminals (G.mgfast). G.mgfast is expected to enable multi-gigabit data rate over twisted-wire pair; 4 Gbps at frequency range up to 424,0 $\mathrm{MHz}$, and $8 \mathrm{Gbps}$ at frequency range up to $848,0 \mathrm{MHz}$. It is evident that the higher frequency range is used to achieve the higher data rate. However, transmission on higher frequencies leads to the fact that cable starts to act as an antenna radiating electromagnetic waves in frequencies already used by different radio services (Fig. 3).

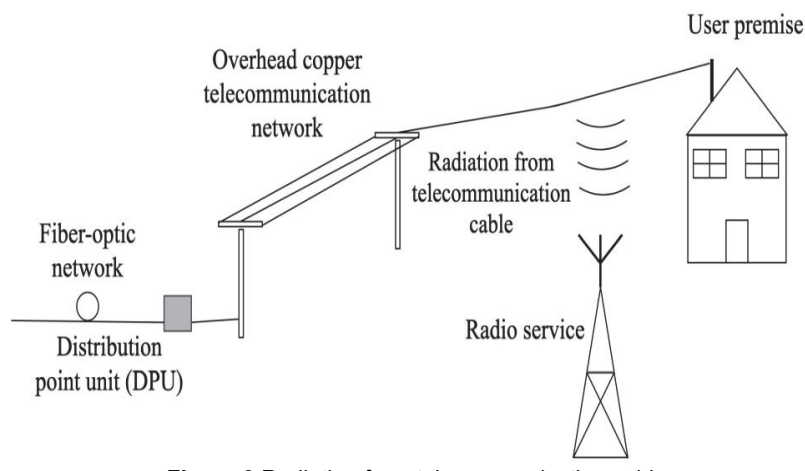

Figure 3 Radiation from telecommunication cable

In order to reduce the radiation from the cable, ITU introduced power spectral density (PSD) shaping method and method of notching the specific frequency bands [11]. While PSD shaping allows reduction of the transmitted power in some parts of the spectrum, notching method, based on the needed protection, provides individually turning off subcarriers on one or more frequency bands. Although proposed notching method generally increases spectrum compatibility and coexistence with radio services, in some cases its application is limited due to the specific radio service operation. For example, application of the notching method is limited in HF band, since radio services in HF band, due to the nature of the propagation in the ionosphere, tend not to use the same frequency all the time. So to protect radio services in HF band different notches are required at different times of day making this method impractical for use [12]. Additionally, to provide some order and to limit radiation from copper telecommunication cable, various radiation limits have been proposed.

\section{RADIATION LIMITS FOR CABLE TRANSMISSION NETWORKS}

Radio spectrum refers to a specific range of frequencies that are essential for many radio services that people daily use. Demand for radio spectrum is rapidly increasing due to increased number of wireless devices, increased requirement for higher broadband throughput, increased usage of multimedia services, etc. Since radio frequency spectrum is finite natural resource, it should be managed in objective, professional and efficient way.

Radio signals at the same frequencies can interfere with each other, causing degradation of the radio signal reception. To prevent unwanted emission and assure adequate interference protection for radio users, radio spectrum has to be managed and monitored by national and/or international administrations. Radio spectrum management at global level is administered by the ITU while the radio spectrum at the European level is regulated by the Conference of European Post and Telecommunication administrations (CEPT) and Electronic Communication Committee (ECC). In the United States, the agency responsible for nongovernmental and non-military use of the frequency spectrum is under jurisdiction of the Federal Communications Commission (FCC).

Services which can be affected by the cable radiation when G.fast signal is passing through the copper twistedwire pairs are: amateur services, aeronautical services, maritime services, broadcasting services, government services and various public safety services. While some service are used only for educational or entertainment purposes, other radio services play very important role in public protection and disaster relief, or they are used by military or government department where any unwanted interferences could cause malfunction of system work and endanger human lives.

In order to avoid interference between DSL systems and radio services operating in the same frequency range, various radiation limits for copper telecommunication networks have been proposed. While some limits proposed by international institutions have a status of recommendation, others are defined by national telecommunication authorities and have the status of current or imminent legal regulation in particular country. Generally, radiation limits proposed by national authorities (e.g. Germany, United Kingdom, Ireland, etc.) overrule the limits proposed by the international institutions.

To minimize electromagnetic disturbance of radio services, ITU proposed ITU-T K.60 recommendation. This recommendation provides protection limits against interference from copper telecommunication networks. Radiation limits defined by the ITU for frequency range from $1,0 \mathrm{MHz}$ to $230,0 \mathrm{MHz}$ are shown in Tab. 1 [13]. ITU-T K.60 recommendation also contains procedure related to investigation of complaints of radio interference and procedure for the assessment of the radiated disturbance emission.

Table 1 Radiation limits proposed in the ITU-T K.60 recommendation

\begin{tabular}{|c|c|c|c|}
\hline $\begin{array}{c}\text { Frequency } \\
\text { range } / \mathrm{MHz}\end{array}$ & $\begin{array}{c}\text { Field strength limit } \\
/ \mathrm{dB} \mu \mathrm{V} / \mathrm{m}\end{array}$ & $\begin{array}{c}\text { Standard } \\
\text { measurement } \\
\text { distance } / \mathrm{m}\end{array}$ & $\begin{array}{c}\text { Measuring } \\
\text { bandwidth / } \\
\mathrm{kHz}\end{array}$ \\
\hline 1 to 30 & $\begin{array}{c}52- \\
8,8 \cdot \log _{10}(\mathrm{f}[\mathrm{MHz}])\end{array}$ & 3 & 9 \\
\hline 30 to 230 & 40 & 3 & 120 \\
\hline
\end{tabular}

Another document that is frequently used as a referent document for assessment of the radio interferences caused by radiation from copper telecommunication networks is $\mathrm{ECC} / \mathrm{REC} /(05) 04$ recommendation. This radiation limit is taken from Germany's Usage Provision 30 ("NB30") and was made as a compromise between operator and radio service needs. Radiation limits defined by the ECC for frequency range from $1 \mathrm{MHz}$ to $1000 \mathrm{MHz}$ are shown in Tab. 2 [14]. 
Table 2 Radiation limits proposed in the $\mathrm{ECC} / \mathrm{REC} /(05) 04$ recommendation

\begin{tabular}{|c|c|c|c|}
\hline $\begin{array}{c}\text { Frequency } \\
\text { range } / \mathrm{MHz}\end{array}$ & $\begin{array}{c}\text { Field strength limit } \\
/ \mathrm{dB} \mu \mathrm{V} / \mathrm{m}\end{array}$ & $\begin{array}{c}\text { Standard } \\
\text { measurement } \\
\text { distance } / \mathrm{m}\end{array}$ & $\begin{array}{c}\text { Measuring } \\
\text { bandwidth } / \\
\mathrm{kHz}\end{array}$ \\
\hline 1 to 30 & $\begin{array}{c}40- \\
8,8 \cdot \log _{10}(\mathrm{f}[\mathrm{MHz}])\end{array}$ & 3 & 9 \\
\hline 30 to 1000 & 27 & 3 & 120 \\
\hline
\end{tabular}

In Tab. 3 radiation limits for copper telecommunication network (unintentional radiators) specified by FCC Volume 47 Part 15 are presented. According to FCC, unintentional radiator is defined as a device that sends radio frequency signals to associated equipment via connecting wiring, but which is not intended to emit RF energy [15].

Table 3 Radiation limits proposed by FCC Volume 47 Part 15 recommendation
\begin{tabular}{|c|c|c|c|}
\hline $\begin{array}{c}\text { Frequency } \\
\text { range / MHz }\end{array}$ & $\begin{array}{c}\text { Field strength limit } \\
/ \mathrm{dB} \mu \mathrm{V} / \mathrm{m}\end{array}$ & $\begin{array}{c}\text { Standard } \\
\text { measurement } \\
\text { distance / } \mathrm{m}\end{array}$ & $\begin{array}{c}\text { Measuring } \\
\text { bandwidth / } \\
\mathrm{kHz}\end{array}$ \\
\hline 1,705 to 30 & 29,5 & 30 & 9 \\
\hline 30 to 88 & 40,0 & 3 & 120 \\
\hline 88 to 216 & 43,5 & 3 & 120 \\
\hline
\end{tabular}

The process of defining the radiation limit values is neither simple nor easy, and it must include many factors such as impact on industry, as well as operator and user needs. In many cases compromise between different needs is harmonized, which is not always the best solution, at least not from the users point of view. Previously mentioned recommendations, national or international, can vary up to a few dozen decibels between each other, as shown in Fig. 4.

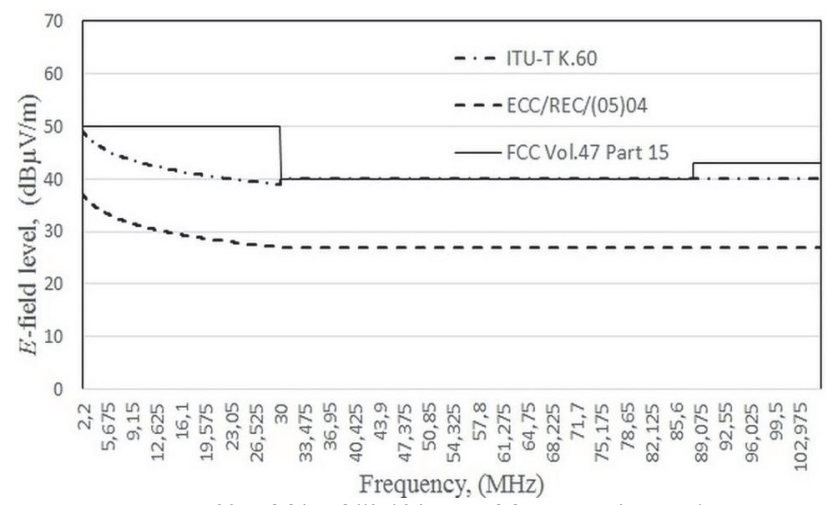

Figure 4 ITU-T K.60, ECC/REC/(05)04 and FCC Volume 47 Part 15 radiation limits in a frequency range from $2,2 \mathrm{MHz}$ to $106,0 \mathrm{MHz}$ (G.fast, profile116a)

In order to compare FCC limits with limits proposed by the ITU-T K.60 and ECC/REC/(05)04 recommendation in Fig. 4, FCC limits for frequency range from $1,705 \mathrm{MHz}$ to $30 \mathrm{MHz}$ were scaled to $d=3 \mathrm{~m}$. This conversion from one distance to the other was made by adding the commonly used "1/d" attenuation factor (i.e. $20 \log$ $(d($ meters $) / 3)=20 \mathrm{~dB})$. From Fig. 4 it is clear that $\mathrm{ECC} / \mathrm{REC} /(05) 04$ recommendation has approximately 15 $\mathrm{dB}$ stronger criteria than ITU-T K.60 and FCC Volume 47 Part 15 recommendation. Although ECC proposed radiation limits that are stricter than those proposed by ITU and $\mathrm{FCC}$, it is hard to say that $\mathrm{ECC} / \mathrm{REC} /(05) 04$ provides adequate protection for all radio services operating in the same frequency range as G.fast. The reason for that lies mainly in the fact that the immunity of the radio system to interference depends on receiver sensitivity which can be set up at much lower level than the level proposed by radiation limit values, e.g. amateur radio receiver can receive signal as low as $1 \mu \mathrm{V} / \mathrm{m}[7]$.

\section{MEASUREMENT METHODOLOGY}

G.fast can provide ultra-fast broadband services by transmitting high frequency signals using existing copper telecommunication infrastructure. Since copper telecommunication infrastructure was not primarily designed for data transmission on such high frequencies, radiation from cable occurs. In order to evaluate radiation level from overhead copper telecommunication network when G.fast signal is transmitted, measurements of the Efield radiation level in the city of Split, Croatia, were carried out. For measurement purposes R\&S ESMD receiver, antenna type $\mathrm{R} \& \mathrm{~S}$ BN150012 and antenna type R\&S HF309 have been used. Antenna R\&S BN150012 is passive magnetic loop antenna with $0,8 \mathrm{~m}$ diameter which is design for frequency range up to $30 \mathrm{MHz}$ while $\mathrm{R} \& \mathrm{~S}$ HF309 is active vertical dipole antenna designed for frequency range from $20,0 \mathrm{MHz}$ to $1,3 \mathrm{GHz}$.

This paper analyses radiation from telecommunication cable when G.fast signal is transmitted through the overhead unshielded TK 33-U telecommunication cable. This cable is often used in the Croatia access network and it consists of three elements containing four wires with 0,4 $\mathrm{mm}$ diameter which are twisted around each other in a star quads $(3 \times 4 \times 0,4 \mathrm{~mm})$. Since TK $33-\mathrm{U}$ cable is not shielded with aluminum tape, higher radiation could be expected from that cable in comparison with the shielded cables designed for data transmission on higher frequencies (e.g. TK 59U-xDSL). To increase protection from external influences (mechanical and weather influences) the cable is covered with polyethylene sheath. TK 33-U cable (total length of $L=173 \mathrm{~m}$ ) was hanged between four poles and G.fast modems are connected to the cable ends. The height of the telecommunication cable is 4 $\mathrm{m}$ above ground level. The measurement set-up for measuring E-field radiation from TK 33-U cable is shown in Fig. 5.

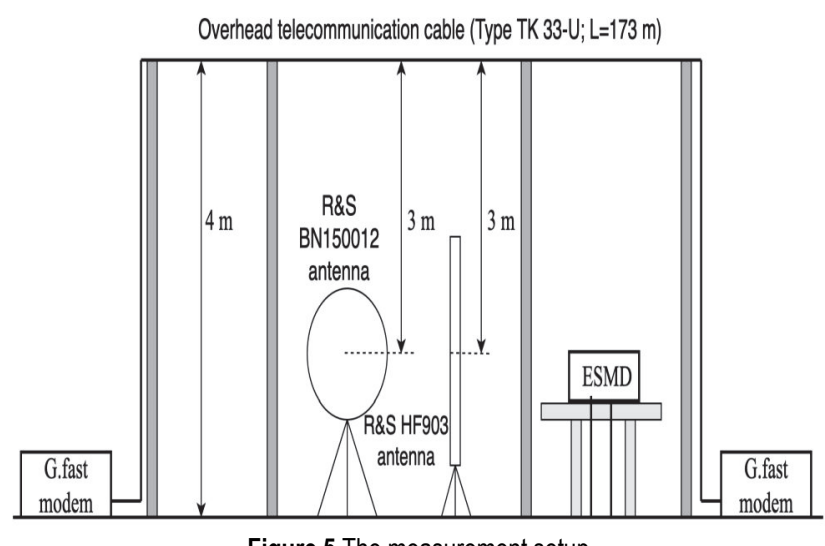

The Rhode \& Schwarz ESMD receiver was set up to measure frequency range from $2,2 \mathrm{MHz}$ to $106,0 \mathrm{MHz}$ (G.fast, profile 106a) with $25 \mathrm{kHz}$ frequency step. All measurements were carried out with a peak detector and measuring bandwidth specified in tables $1 \div 3$. In order to get E-field level in $\mathrm{dB} \mu \mathrm{V} / \mathrm{m}$, antenna correction factor, 
cable loss as well as connector loss were added to the values measured at the receiver. The antennas were mounted on the masts at $3 \mathrm{~m}$ below the cable. After the loop antenna was placed at the proper location and receiver was set up to the required parameters, antenna was rotated around vertical axis so that the position of the maximum received signal could be found as is specified in [13]. Once the required loop antenna position has been found, the measurement procedure started.

\section{EXPERIMENTAL RESULTS}

In order to decrease the influence of the ambient noise to the measurement results, measurements were carried out in the rural area near the city of Split, Croatia. G.fast modems were set up to the aggregate power of the $4 \mathrm{dBm}$, according to the [11]. In order to obtain the referent E-field level in the frequency range from $2,2 \mathrm{kHz}$ to $106,0 \mathrm{MHz}$ measurement was firstly made when G.fast signal was not transmitted via the TK 33-U cable (no radiation from the cable). Measurements were carried out when the antennas were set up 3 m below overhead TK 33-U cable. The result of this measurement is presented in Fig. 6. Narrow band signals with magnitude higher than the $15 \mathrm{~dB}$ above the noise level are signals transmitted by the radio services.

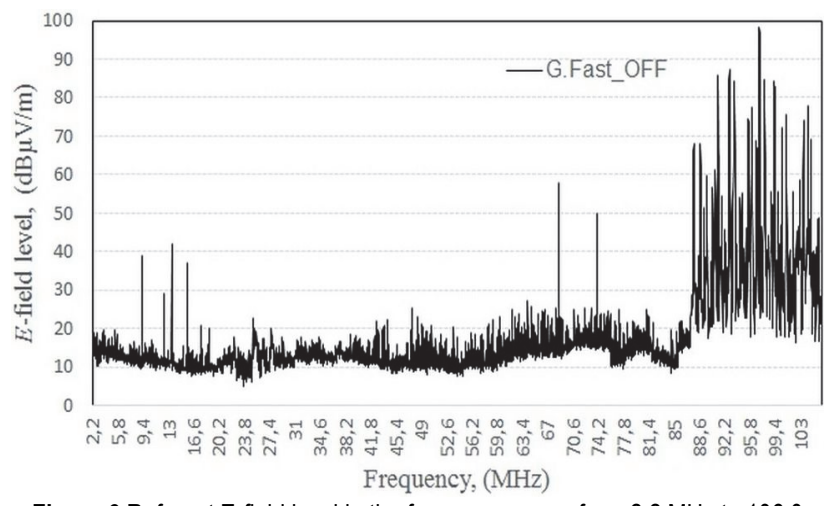

Figure 6 Referent E-field level in the frequency range from 2,2 MHz to 106,0 $\mathrm{MHz}$

Intention of this research is to perform measurements in the realistic radio environment. Unfortunately, drawback of this approach is that not all environment variables could be controlled. For example, at measuring location strong FM broadcasting radio signals in frequency range from $87,5 \mathrm{MHz}$ to $108,0 \mathrm{MHz}$ was received with magnitude much higher than magnitude of the signals radiated from the TK 33-U cable. Consequently, radiation from the TK 33-U cable cannot be analysed in the frequency range occupied by FM broadcasting stations.

Comparison between cable radiation when a G.fast signal is transmitted through one twisted-wire pair and the referent E-field level is shown in Fig. 7. Fig. 7 shows that the radiation level when G.fast signal was transmitted was increased by approximately $6 \mathrm{~dB}$ compared to the average referent value measured when G.fast modems were switched off. Maximum radiation is measured at 78,9 $\mathrm{MHz}$ and it is $33,1 \mathrm{~dB} \mu \mathrm{V} / \mathrm{m}$. In order to analyse the cumulative effect of radiation of several twisted-wire pairs, E-field radiation was measured when G.fast signal was simultaneously transmitted over six twisted-wire pairs.
Measurement results of the cumulative twisted-wire pairs radiation are presented in Fig. 8.

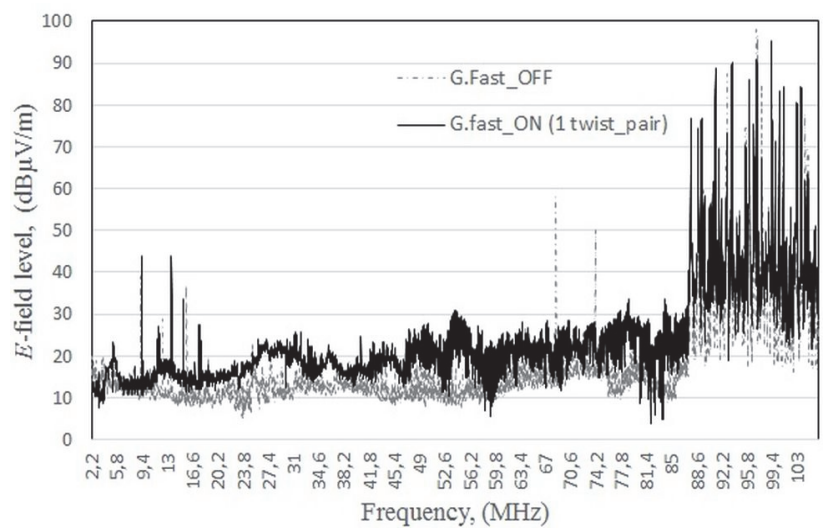

Figure 7 Measured E-field level in the frequency range from 2,2 $\mathrm{MHz}$ to 106,0 $\mathrm{MHz}$

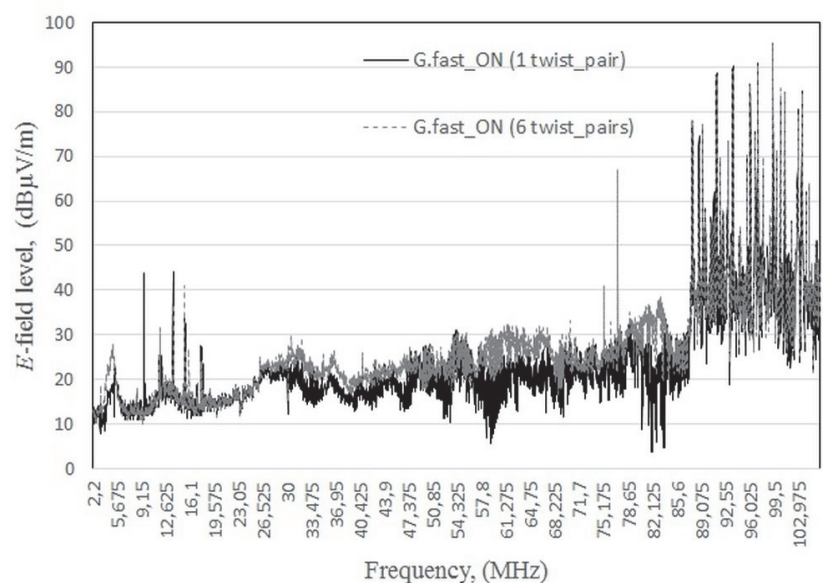

Figure 8 Measured E-field radiation from one twisted-wire pair and six twisted wire pairs

Fig. 8 presents the fact that average radiation increases for approximately $2,6 \mathrm{~dB}$ when G.fast signal was transmitted over six twisted-wire pairs compared with the result obtained when one twisted-wire pair was used for data transmission. This increase in radiation is not critical and it can cause problem with reception of radio signal only if signal to noise ratio (SNR) of the radio signal received by the receiver is close to the receiver sensitivity. If radiation from the G.fast data-carrying cable is too high, the reception of wanted radio signals can become difficult or impossible. To enable undisturbed reception of wanted radio signals, various radiation limits for copper telecommunication networks have been proposed. Mostly used radiation limits are defined in ITU-T K.60, ECC/REC/(05)04 and FCC Volume 47 Part 15 recommendation, presented in section 4. Fig. 9, presents the comparison between the measured E-field values and the recommended radiation limits when the G.fast data carrying TK 33-U telecommunication cable was used.

Fig. 9 shows that, depending on the given recommendation, different conclusions can be drawn regarding comparison between E-field cable radiation and proposed radiation limits. As it can be seen in Fig. 9, radiated power in the observed frequency range is below radiation limit values proposed in the ITU-T K.60 and FCC Volume 47 Part 15 recommendation. That leads to the conclusion that limits proposed by the ITU and FCC are 
too pessimistic allowing greater radiation from telecommunication network. Contrary to ITU and FCC, radiation limits proposed by the ECC are too optimistic in terms of radiation. That is seen in a part of the observed frequency range, presented in Fig. 9, where measured Efield values are above limit values proposed in the $\mathrm{ECC} / \mathrm{REC} /(05) 04$ recommendation. Maximum radiation is measured at $78,9 \mathrm{MHz}$ and it is $33,5 \mathrm{~dB} \mu \mathrm{V} / \mathrm{m}$. According to the limit values presented in table 2 it is $6,5 \mathrm{~dB}$ above limits value defined in $\mathrm{ECC} / \mathrm{REC} /(05) 04$ recommendation.

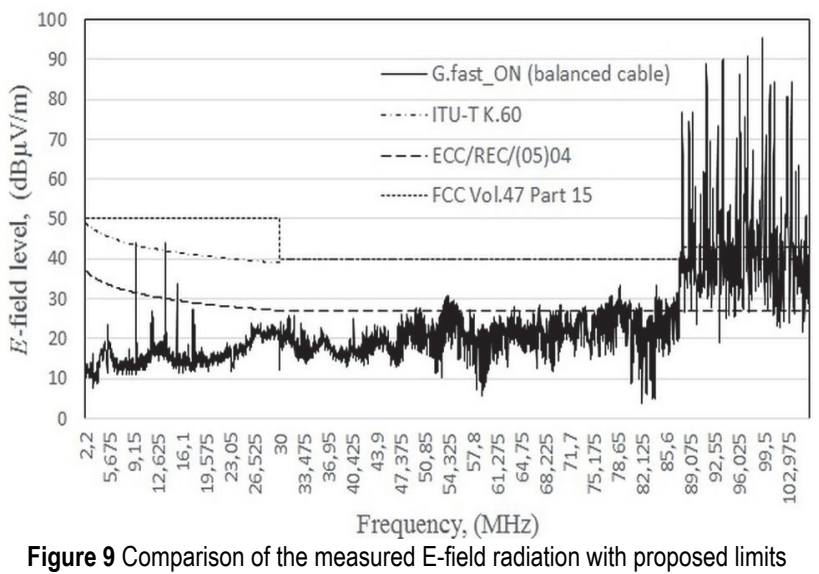

If the wires are not perfectly balanced, a commonmode signal will appear due to the introduced differences in amplitude and phase of the signals in the cable. That will increase radiation from the telecommunication cable. In practice, this scenario can happen when one of the wires of the twisted-wire pairs is disconnected. To compare radiation level from the balanced and the unbalanced cable and to get the insight of how much the radiated E-field level can differ, the measurement was repeated when one wire from the twisted-wire pairs was disconnected (unbalanced cable). Measurement results of the E-field radiation when the balanced and the unbalanced cable were used are shown in Fig. 10.

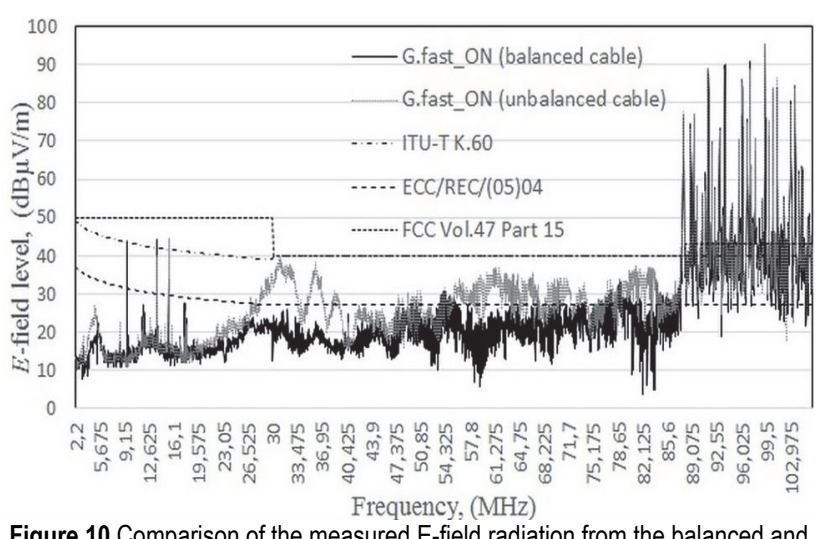

Figure 10 Comparison of the measured E-field radiation from the balanced and the unbalanced cable with proposed limits

Fig. 10 clearly shows that radiation from the unbalanced cable is higher than radiation from the balanced cable. In particular, average value of the radiation is $5 \mathrm{~dB}$ higher when the unbalanced cable is used than in case when balanced cable is used. Maximum radiation when the unbalanced cable is used is measured at $30,85 \mathrm{MHz}$ and it is $39,6 \mathrm{~dB} \mu \mathrm{V} / \mathrm{m}$. That is $12,6 \mathrm{~dB}$ above limit value defined in $\mathrm{ECC} / \mathrm{REC} /(05) 04$ recommendation at the same frequency and only $0,4 \mathrm{~dB}$ below radiation limits proposed in ITU-T K.60 and FCC Volume 47 Part 15 recommendation.

According to the increase in radiation when the unbalanced cable is used it is evident that radiation from the unbalanced cable can cause serious problem with radio signal reception and disable radio services operation as intended. Therefore, this situation has to be avoided whenever possible. The situation related to radiation from the unbalanced cable can be even worse if distance between telecommunication cable and radio antenna is less than $3 \mathrm{~m}$, due to the fact that path loss decreases as the distance between the antenna and the cable decreases.

\section{CONCLUSION}

G.fast provides an economical alternative to fiberoptic technology, eliminating the high cost of "fibering" at the last few hundred meters to the user premises ("last mile"). Unfortunately, transmitted signal causes radiation from the copper telecommunication network, which is especially a concern for the radio services operating in the same frequency range. The aim of this paper is to investigate radiation from the unshielded TK 33-U telecommunication cable when G.fast (profile 106a) signal is transmitted. Presented results show that radiation from the cable increases by approximately $6 \mathrm{~dB}$ when G.fast signal is transmitted through twisted-wire pair compared to the averaged referent E-field value (ambient noise) when G.fast signal is not transmitted. Additionally, radiation from cable when the unbalanced cable was used was also measured. As expected, measurement results show that radiation increases when the unbalanced cable is used in comparison with the case when the balanced cable is used. The average value of the radiation is increased by approximately $5 \mathrm{~dB}$.

In order to ensure that radiated emission from the telecommunication network does not prevent other radio services from operating properly, the different radiation limits have been proposed. To assess whether or not radiation from the TK 33-U telecommunication cable meets radiation limits, comparison between measured Efield radiation values and radiation limit values is also given. Measurement result show that the radiation limits proposed by the ITU-T K.60 and FCC Volume 47 Part 15 recommendation was fulfiled even when the unbalanced cable is used, while radiation limits proposed by the $\mathrm{ECC} / \mathrm{REC} /(05) 04$ recommendation underestimates cable radiation in the case of the use of balanced as well as unbalanced cables. In particular, at $78,9 \mathrm{MHz}$ the radiation from cable is $6,5 \mathrm{~dB}$ above the $\mathrm{ECC} / \mathrm{REC} /(05) 04$ radiation limit value when the balanced cable is used and $12,6 \mathrm{~dB}$ above the limit value at $30,85 \mathrm{MHz}$ when the unbalanced cable is used. Since level of interference depends on a distance between telecommunication cable and radio antenna, even higher level of radiation and higher disturbances to radio signal reception could be expected in the case of smaller distance (less than $3 \mathrm{~m}$ ) from the overhead telecommunication network. 


\section{Acknowledgements}

This paper and research behind it would not have been possible without the exceptional technical and financial support of the Croatian regulatory authority for network industries (HAKOM). We would also like to thank the following people, without whom we would not have been able to complete this research, Goran Jurin M.Sc. for his enthusiasm, motivation and immense knowledge; and our colleagues from RF Spectrum Monitoring department, for their assistance with the collecting the data and insightful comments.

\section{REFERENCES}

[1] Alobaidan, H. (2017). Current and future FTTH technologies. Journal of Wireless Networking and Communications, 7(2), 35-40.

[2] Wei, D., Fazlollahi, A., Long, G., \& Wang, E. (2014). G.fast for FTTdp: Enabling gigabit copper access. 2014 IEEE Globecom Workshops (GC Wkshps), 668-673. https://doi.org/10.1109/GLOCOMW.2014.7063509

[3] Freeman, R. L. (2005). Fundamentals of telecommunications. New Jersey, Wiley Interscience. https://doi.org/10.1002/0471720941

[4] V, Okman., Strobel, R., Wang, X., Wei, D., Verbin, R., Goodson, R., \& Sorbara, M. (2016). The ITU-T's new G.fast standard brings DSL into the gigabit era. IEEE Communications Magazine, 54(3), 118-126. https://doi.org/10.1109/MCOM.2016.7432157

[5] Stolle, R. (2002). Electromagnetic coupling of twisted pair cables. IEEE Journal on Selected Areas in communications, 20(5), 883-892. https://doi.org/10.1109/JSAC.2002.1007371

[6] Olsen, R. (2005). Technical considerations for broadband powerline (BPL) communication.

[7] Clercq, L. De., Peeters, M., Schelstrate, S., \& Pollet, T. (2000). Mitigation of radio interference in xDSL transmission. IEEE Communications Magazine, 38(3), 168173. https://doi.org/10.1109/35.825655

[8] Paul, C. R. (1992). Introduction to electromagnetic compatibility. New York, Wiley Interscience.

[9] Statovci, D., Wolkerstorfer, M., \& Drakulic, S. (2017). Prequalification of VDSL2 customers for G.fast services. $25^{\text {th }}$ European signal processing conferece (EUSIPCO), 2244-2248. https://doi.org/10.23919/EUSIPCO.2017.8081609

[10] Fast access to subscriber terminals (G.fast)-Physical layer specification. (2014). ITU-T G.9701.

[11] Fast access to subscriber terminals (G.fast)-Power spectral density specification. (2017). ITU-T G.9700.

[12] Stott, J. (2006). Potential threats to radio services from PLT systems. EBU Technical review.

[13] Emission level and test methods for wireline telecommunication networks to minimize electromagnetic disturbance of radio services. (2003). ITU-T K.60.

[14] Criteria for the assessment of radio interferences caused by radiated disturbances from wire-line telecommunication networks. (2005). ECC/REC/(05)04.

[15] Radiated emission limits; general requirements. Federal Communications Commission (FCC), 47(15).

\section{Contact information:}

Josip MILANOVIC, PhD, Assistant Professor

(Corresonding author)

Croatian egulatory authority for network industries,

R. F. Mianovica 9, 10000 Zagreb, Croatia

E-mail: josip.milanovic@hakom.hr

Snjezana RIMAC-DRLJE, PhD, Full Prof. tenure

J. J. Strossmayera University of Osijek

Faculty of electrical engineering, computer science and information technology

Osijek,

Kneza Trpimira 2b, 31000 Osijek, Croatia

E-mail: snjezana.rimac@ferit.hr 